\title{
A Interface da Responsabilidade Social na Gestão de Recursos Naturais ${ }^{1}$
}

\section{The Interface of Social Responsibility in the Management of Natural Resources}

\author{
José Mancinelli Lêdo do Nascimento \\ Doutorando em Recursos Naturais/Universidade Federal de Campina Grande Rua, Aprígio Veloso, 822, Bairro \\ Universitário, CEP: 58.429-900, Campina Grande, PB.e-mail: jm-ledo@uol.com.br \\ Rosires Catão Curi \\ $D r^{\underline{a}}$ Systems Design Engineering - University of Waterloo, Canadá. Professora do Programa de Pós- \\ Graduação em Recursos Naturais - PPGRN/UFCG. Rua, Aprígio Veloso, 822, Bairro Universitário, CEP: \\ 58.429-900. Campina Grande, PB. e-mail:rosirescuri@yahoo.com.br
}

\section{RESUMO}

Este estudo tem como objetivo apresentar uma abordagem teórica da interface da responsabilidade social na gestão de recursos naturais. Utiliza-se das definições de organização, gestão e responsabilidade social fundamentado no pressuposto de que os modelos de gestão são baseados em um sistema de valores e que eles refletem no modo como as organizações operam. A compreensão da importância desta interface permite uma reflexão sobre as variáveis integrantes do modelo GREEN, em uma perspectiva contemporânea, e, ao mesmo tempo, ampliar o leque de possibilidades nas discussões entorno das dinâmicas dos processos naturais e sociais, sobretudo em relação ao uso dos recursos naturais. Evidencia a responsabilidade social na gestão de recursos naturais, tomando como referencial o trabalho dos autores: Carrol (1991), Vieira e Weber (2002); e Ashley (2003), A abordagem engloba a importância dos valores morais e éticos no funcionamento de um sistema de gestão, as organizações como fonte aglutinadora de pessoas em busca de soluções de problemas e, por fim, a melhoria da qualidade da gestão de recursos naturais, em decorrência da inclusão de novos métodos de gestão com base na responsabilidade social.

Palavras-Chave: Organização, Gestão, Responsabilidade Social, Valores.

\section{ABSTRACT}

This study has as objective to present a theoretical approach of the interface of social responsibility in natural resources management. It uses the definitions of organization, management and social responsibility based on the conjecture in which the models of management are fundament of a system of values and they reflect the way the organizations function. The comprehension of the importance of this interface allows a reflexion about the variables component of the model GREEN, in a contemporaneous perspective, and, at the same time, increases the amount of possibilities of discussions that surround the dynamic of natural and social procedures, especially in relation to the use of natural resources. It puts in evidence the social responsibility in natural resources management, using as referential the work of the authors: Carrol (1991), Vieira and Weber (2002), and Ashley (2003). The approach embody the importance of the moral and ethical values at the function of a system of management, the organizations as source of people searching for solutions of problems and, finally, the improvement in the quality of management of natural resources, in consequence of the inclusion of the new methods of management based on the social responsibility.

Key words: Organization, Management, Social Responsibility, Values.

\footnotetext{
1 Artigo recebido em 26.01.2013. Avaliado por pares em 13.02.2013 (blind review). Reformulado em 18.03.2013. Recomendado para publicação em 29.03.2013 por José Ribamar Marques de Carvalho (Editor). Publicado em 01.04.2013. Organização responsável pelo periódico: UACC/UFCG.
}

REUNIR - Revista de Administração, Contabilidade e Sustentabilidade ISSN: 2237-3667 - Vol.3, no 1, Jan./Abr., p. 44-61, 2013. 


\section{INTRODUÇÃO}

Em todo o mundo, as organizações têm sido impulsionadas a buscar melhorias contínuas em seu desempenho, para reduzir as consequências das mudanças que impactam a sociedade e inquietam grande parte dos pesquisadores em relação a previsão de cenários futuros, no que diz respeito às questões ambientais e sociais e, assim, monitorar as variáveis que podem ameaçar a biodiversidade. Torna-se, portanto, imperativo que o conjunto da sociedade civil organizada e as organizações públicas e privadas adotem uma nova postura quanto ao seu envolvimento e condução do meio ambiente no qual estão inseridos.

A reflexão sobre o meio ambiente perpassa pela necessidade de uma abordagem holística e a aplicação de um método interdisciplinar que permitam a integração das ciências da natureza e da sociedade, concentrando suas atenções na conservação dos recursos naturais e preservação da biodiversidade, em perspectiva do ideal material, econômico, tecnológico e cultural.

Para enfrentar as demandas dessa nova abordagem, as organizações precisam adotar novos modelos e ferramentas de gestão que tratem o meio ambiente como um valor social, independente das imposições legais. A inclusão de práticas relacionadas à Responsabilidade Social (RS) conduz as organizações a um novo gerenciamento, que além da busca pelo sucesso comercial, tem como pressupostos básicos: valores éticos, respeito às pessoas, comunidades e meio ambiente natural (BSR, 2006).

A aplicação dos conceitos referentes à RS é visto como uma necessidade provocada pelo contexto contemporâneo no qual as organizações e as pessoas devem estar inseridas. E para conduzir a organização a uma nova abordagem de gestão, sob a ótica ambiental, é preciso compreendê-la, preferencialmente, de forma sistêmica e a correlação da causa e efeito de suas atividades em relação ao meio ambiente.

Segundo Egri e Pinfield (1998), as atividades organizacionais não são independentes dos sistemas. Elas também absorvem recursos e suprimentos, que são transformados, para gerarem produtos (outputs) para o ambiente social maior. Ou seja, as organizações estão presentes no meio ambiente, do qual recebem insumos, transformam e colocam os seus produtos para serem consumidos, através de bens, serviços e informações.

Ashley (2003) considera que os objetivos empresariais transcendem os fatores de produção e as organizações devem conciliar interesses do individuo, da sociedade e da natureza, transitando do paradigma antropocêntrico, no qual a empresa é o centro de tudo, para o ecocêntrico, no qual o meio ambiente é o mais importante, e a empresa, assim como outros agentes, insere-se nele.

Estabelecer diretrizes de longo prazo para a gestão de recursos naturais requer a construção de modelos sistêmicos que permitam visualizar a relevância da mudança do paradigma vigente para o ecocêntrico, na percepção e no 
comportamento dos atores sociais, visando a construção de uma nova ordem de interações com a natureza.

Essas diretrizes devem conter as definições de práticas de gestão que possam garantir os resultados esperados pelos atores sociais envolvidos no processo e que preservem os recursos naturais. Devem ser ancoradas na análise das condições externas, materiais e sociais, e no exercício da atividade econômica, além de se buscar dispositivos institucionais que norteiam a sociedade.

Para Godard, (2002) a promoção de uma gestão integrada de recursos naturais e do meio ambiente pode nos levar não só ao questionamento de certas modalidades técnicas de exploração, mas também estimular a busca de transformações das condições sociais que cercam seu exercício.

Propõe-se, então, neste estudo, um ensaio teórico que objetiva evidenciar a interface da RS na gestão de recursos naturais tomando como referencial o modelo compacto de análise GREEN, adaptado por Vieira e Weber (2002), e as abordagens de Carrol (1991) e Ashley (2003), considerando que: o funcionamento de um sistema de gestão na sua efetividade e eficiência depende de como os atores sociais e organizacionais incorporam valores morais e éticos; o papel relevante das organizações públicas, privadas e informais como fonte aglutinadora de pessoas para solução de problemas; a inclusão de novos métodos gerenciais em busca da melhoria da qualidade da gestão.

$\mathrm{Na}$ estrutura proposta para este ensaio, parte-se de um breve relato sobre organização e gestão, seguido de algumas considerações sobre responsabilidade social e finalmente procura-se estabelecer a interface entre responsabilidade social e a gestão de recursos naturais.

\section{Modelo GREEN no contexto da gestão}

Ao longo do tempo, as organizações foram sistematicamente incorporando novos valores culturais e aperfeiçoando suas normas administrativas, forma de poder e de decisão, sem maiores preocupações com as questões ambientais. No contexto atual, qualquer tipo de organização, seja do segmento privado, de arranjos estatais ou não governamentais, precisa adotar novos modelos de gestão, que melhorem os seus padrões de eficiência e garantam a melhoria da qualidade ambiental numa visão sistêmica para um desenvolvimento viável.

$\mathrm{Na}$ abordagem da Teoria de Sistema, as propriedades dos sistemas não podem ser descritas separadamente e só é possível compreendê-los quando se estuda como o todo. Assim sendo, e levando em consideração a complexidade das relações estabelecidas e dos fatores de produção, a organização pode ser considerada: 
idêntico às finalidades individuais dos membros dos grupos. (...) As organizações sociais são flagrantemente sistemas abertos, porque o insumo de energias e a convenção do produto em novo insumo de energia consistem em transações entre a organização e seu meio ambiente (KATZ e KAHN 1987, apud CURY, 2006, p. 118).

Portanto, nas mais diversas atividades desenvolvidas pelo homem, individualmente e/ou de forma coletiva nas organizações, não se pode deixar de considerar o meio ambiente, pois dele são extraídos os recursos naturais para produção e, posteriormente, são devolvidos em formas de produtos, serviços e resíduos sólidos. Nesse ciclo, o uso dos recursos naturais vem crescendo de forma acelerada e, por consequência, causando ações negativas ao meio ambiente e comprometendo o equilíbrio dos ecossistemas.

Para Vieira e Weber (2002), a crise contemporânea do meio ambiente é decorrente do progressivo esgotamento das várias abordagens de desenvolvimento experimentadas ao longo do tempo. Trata-se também de uma crise da atividade econômica e das instituições reguladoras, causadas pelas contradições paradigmáticas da ideia de que progresso e desenvolvimento são sinônimos de dominação da natureza.

$\mathrm{O}$ aparecimento da gestão de recursos naturais como área de pesquisa, se insere como um dos componentes fundamentais do processo de regulação das relações mútuas dos sistemas socioculturais e do meio ambiente biofísico. Articula-se numa dinâmica que compreende uma sequencia de atividades interativas, entre as práticas econômicas e as de conservação do meio ambiente.

Para nortear a gestão de recursos naturais, Vieira e Weber (2002), apresentam o modelo (figura 1) a dinâmica dos modos de apropriação e gestão de recursos renováveis, desenvolvido pela unidade de pesquisa Gestion de Ressources Naturelles Renouvelables, Environnement (GREEN), sediada no Centre de Coopération Internationale en Recherche Agronomique pour le Développement (CIRAD), que toma por base a aplicação de princípios e métodos da pesquisa de sistemas complexos, 


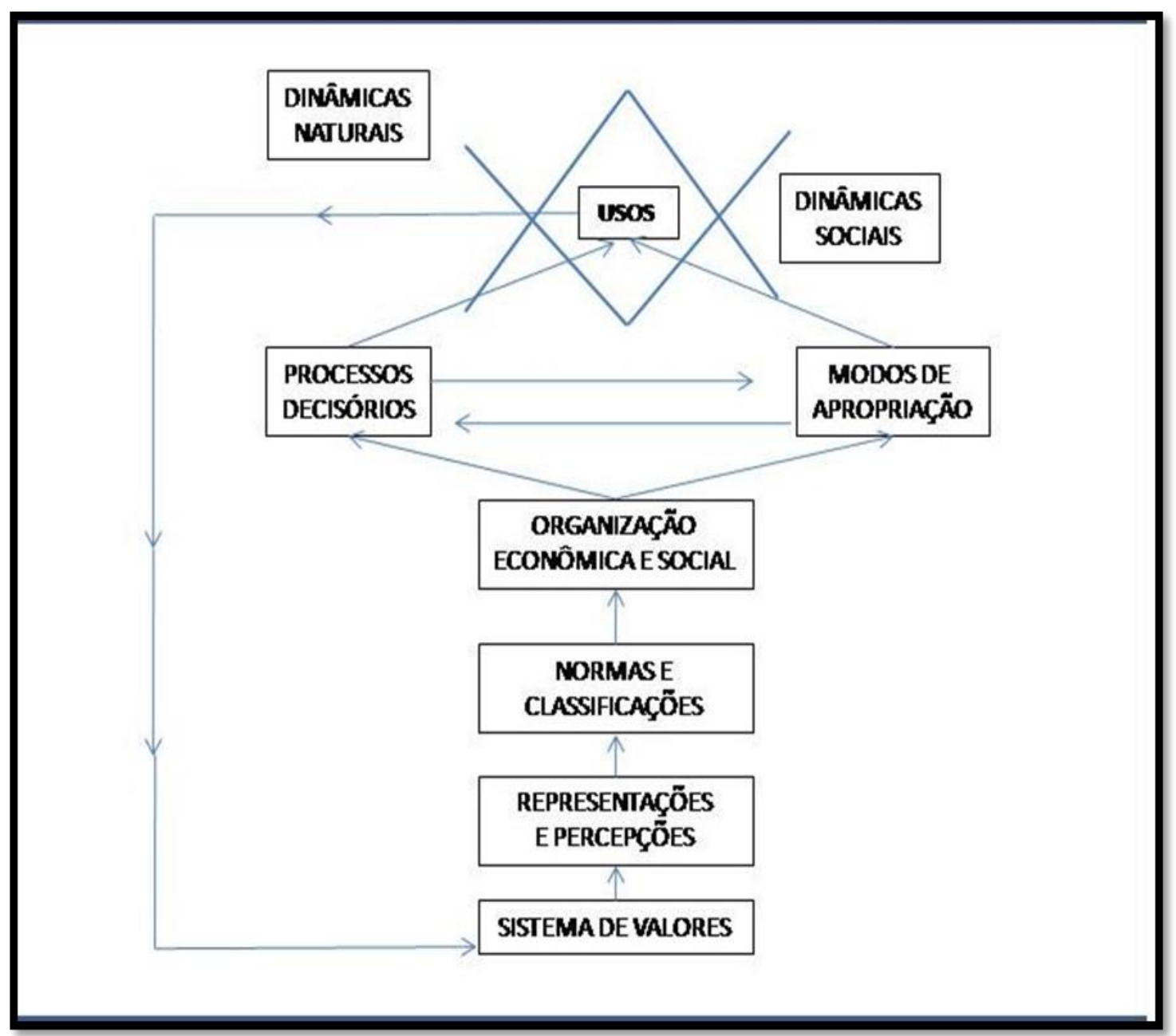

Figura 1. Modelo compacto de análise GREEN

Fonte: Vieira e Weber (2002).

O modelo de gestão proposto leva em conta os usos dos recursos naturais no contexto das dinâmicas naturais e sociais, considerando que os mesmos se transformam como o passar dos anos, dependendo tanto da evolução dos processos naturais, como também da evolução da tecnologia. Para análise do modelo acima proposto, têm-se as seguintes variáveis: modos de apropriação e processos decisórios; organização econômica e social; normas e classificações; representações e percepção e sistema de valores, que devem ser usadas em função do que é requerido de recursos naturais para atender as demandas das necessidades.

Como contribuição para entendimento conceitual de modos de apropriação Vieira, Berkes e Seixas (2005) apresentam quatro tipos de regimes de apropriação que consideram ideais e tendem a ser controlados mediante a combinação entre eles: a) livre acesso - representa a ausência de direitos de propriedade bem definidos, e, por conseguinte incompatível com a sustentabilidade, em virtude da falta de normas e regulamentos; b) propriedade privada - refere-se à situação na qual um indivíduo ou corporação tem o direito de excluir outros e de regulamentar o uso do recurso que se 
apropriou; c) propriedade estatal - significa que os direitos sobre os recursos naturais constituem prerrogativas exclusivas do governo, que controla o acesso e regulamenta o uso; d) propriedade comunal - nesse tipo, o recurso é controlado por uma comunidade definida de usuários, que pode excluir outros usuários e regulamentar a sua a utilização.

Segundo Ollagnon (2002), a titularidade do patrimônio é entendida como aquela que estabelece uma relação com elementos materiais e imateriais do seu meio ambiente e que cada ator social gera seu patrimônio através do envolvimento simultâneo com todas as categorias de titulares, sejam elas pessoa física, jurídica ou comunidade.

Para os processos decisórios, Robbins (2000), apresenta as vantagens das decisões tomadas em grupo, partindo do princípio de que os grupos geram informações e conhecimentos mais completos, pois agregam conhecimentos de vários atores sociais, trazendo mais dados e heterogeneidade para o processo de decisão, além de oferecer maior diversidade de opiniões, abrindo a oportunidade para que mais abordagens e alternativas sejam consideradas.

A ênfase colocada na dimensão organização segundo Vieira e Weber (2002), estimula uma percepção renovada de possibilidade ainda pouco explorada de inovação social. Como importante variável do GREEN, na organização econômica e social, as mudanças de atitudes sobre o compartilhamento dos objetivos institucionais devem ser traduzidas no estabelecimento de metas que possam ser incorporadas e praticadas por todos que a integram, visando alcançar os resultados desejáveis.

Duas propostas são apresentadas para nortear a gestão da inovação social: a primeira, política ambiental antecipativa-preventiva, cuja dimensão de longo prazo permite $\mathrm{o}$ seu aperfeiçoamento constante através das ações das pesquisas interdisciplinares e legitimação na esfera política. A segunda, política ambiental preventiva-adaptativa, cujo ponto de partida perpassa pela discussão sobre sistemas alternativos de valores sociopolíticos, análise das causas que geram as crises de natureza global e o estabelecimento de indicadores sociais e ecológicos que apresentem resultados fidedignos da situação e possibilite a construção e um novo modelo contratual de projetos de sociedade (VIEIRA E WEBER, 2002).

As normas e classificação são variáveis entendidas como a formulação da política de uso dos recursos naturais. Nessa variável o Estado deve liderar as questões relacionadas com os recursos naturais, como instituição, deve estabelecer princípios norteadores para uso dos recursos naturais. Carvalho (2003, p.281) afirma que: "o direito ao meio ambiente, chamado de 'direito de terceira geração', não impõe deveres apenas ao Estado, mas a todos, pessoas físicas ou jurídicas". Para Ollagnon (1990, apud Weber 2002, p. 29), uma concepção alternativa de regulação pode ser extraída do cenário que prevê a possibilidade de representação dos recursos 
transapropriativos mediante a categoria de patrimônio comum, a ser gerido em bases contratuais.

As representações e percepções se apresentam como contraponto aos paradigmas tradicionais de análise, o GREEN focaliza prioritariamente os interesses dos atores na gestão, posteriormente a figura do decisor. O modelo visa dentre outros, identificar as propostas das representações, nas quais emergem objetivos estratégicos a serem compartilhados pelos atores sociais antes do processo de estruturação das possíveis soluções.

Quanto aos sistemas de valores, Ferreira (2004, p.20) interpreta que valores são "as normas, princípios ou padrões sociais aceitos ou mantidos por indivíduo, classe, sociedade". Sendo assim, as decisões são tomadas e ao fazê-las, invocam-se os valores presentes no cotidiano, seja de forma consciente ou inconscientemente, portanto, age-se mediante os valores individuais que se possui. Segundo Nadas (2002), a moral é a ordenação de valores, que orienta as atitudes em função das tomadas de decisões, tendo esse posicionamento um papel fundamental para a sociedade como um todo. Já a ética é a maneira de se pôr em prática os valores morais; um sistema de balizamento ou de codificação a ser usado na tomada de decisões.

\section{Responsabilidade Social e Gestão de Recursos Naturais}

Historicamente, tem-se pautado a temática da RS a partir do período pósrevolução industrial, no início do século $X X$, frente a uma regulamentação de mercado e das políticas abusivas de preços, além do monitoramento da expansão das corporações pelo mundo, especialmente quando o Conselho Econômico e Social da ONU, através da resolução 1721, iniciou estudos sobre o papel das multinacionais nos países emergentes (STONER e FREEMAN, 1999; REBOUÇAS, 2009). Desde então, tem havido uma série de mudanças nas terminologias e, adicionalmente, a proliferação de várias abordagens.

Embora não seja mencionada na literatura de RS, mas com ações de relevância social, Robert Owen no início do século XIX, na qualidade de sócio da algodoaria New Lanark, na Escócia, propôs a criação de várias comunidades industriais para atender as pessoas que trabalhavam e viviam em péssimas condições de higiene e moradia. Ele criou um armazém para atender os trabalhadores, no qual podiam comprar mercadorias a preço módico e estabelecer um rigoroso controle da venda de bebidas alcoólicas, o que resultou na redução dos vícios e de crimes. Do ponto da educação, foi o fundador em 1816, da primeira escola maternal britânica (UNIVERSIDADE FEDERAL DE CAMPINA GRANDE, 2011).

Em 1863, a Grã-Bretanha aprova a primeira lei contra poluição do mundo e cria o primeiro órgão de controle da poluição (BURSZTYN e PERSEGONA, 2008) Na Alemanha, em 1929, inaugura-se a ideia de "função social da propriedade". 
Paralelamente a esses fatos, o aperfeiçoamento dos transportes no século XIX e o acesso à informação na segunda metade do século XX disseminaram o conhecimento sobre as condições do meio ambiente, permitindo que mais pessoas pudessem perceber os impactos ambientais e sociais além dos arredores de suas comunidades (FIGUEIREDO, 2012).

Aos poucos, com os questionamentos de ativistas sociais em relação à prática da discriminação das minorias, dos objetivos econômicos únicos das empresas privadas e suas ações danosas ao meio ambiente, tornam-se crescentes as ideias de intervenção do Estado, como também as exigências de tomada de decisão com base nos aspectos sociais, no que se refere à filantropia; determinação de preços; relações com os funcionários; preservação dos recursos; qualidade de produtos e operações em países que violam os diretos humanos.

Para reforçar ainda mais as correntes de defesa da intervenção do Estado, Upton Sinclair publicou, em 1906, o romance The Jungle (a Selva), no qual narra a realidade da indústria da carne e a forma como era comercializada em Chicago, apesar da proibição no comércio exterior: "A carne misturada com pedaços de tecidos esfarrapados e sujos, pães mofados, moídos juntamente com os enchimentos das linguiças" (SOUZA, 1996. p. 52). As denuncias de Sinclair levaram o presidente dos Estados Unidos, Theodore Roosevelt, a criar uma lei federal de segurança alimentar, denominada Lei da Comida Pura.

As expectativas intervencionistas não são bem vistas pelas indústrias americanas, especialmente frente ao papel desempenhado pelas empresas nos Estados Unidos. A filosofia econômica predominante é de que o governo não deveria interferir nos negócios, que a liberdade de mercado entre oferta e demanda resultaria no uso responsável dos recursos naturais e o contínuo crescimento econômico asseguraria o bem estar das pessoas.

Todo esse processo caminhava com a presença muito forte do Estado na regulação da economia e das obrigações das empresas do ponto de vista social. Entretanto, a ideias contrárias foram surgindo, alguns estudiosos relatavam paralelamente suas impressões de que cabiam ao governo, igrejas, sindicatos e organizações não governamentais o suprimento das necessidades comunitárias através de ações sociais organizadas e não as empresas, para as quais a obrigação, na verdade, era satisfazer os acionistas com resultados financeiros, surgindo daí um processo evolutivo das ideias e significados dos mais variados de RS.

Para Cruz (2006), RS é um conceito amplo, com muitos significados e sinônimos que abrangem a cidadania corporativa, desenvolvimento sustentável, crescimento sustentável, sustentabilidade, capitalismo sustentável, filantropia empresarial, marketing social, ativismo social empresarial. Já para Melo Neto e Froes (2005), RS de uma empresa consiste na sua decisão de participar mais diretamente das ações comunitárias na região em que está presente e diminuir os possíveis danos ambientais decorrente do tipo de atividade que exerce. 
Nesse processo de evolução teórica, Garrida e Melé (2004) consideram que as teorias e os enfoques mais importantes da Responsabilidade Social Corporativa (RSC) estão presentes em quatro dimensões, relacionadas com benefícios, atuação política, demanda social e valores éticos. Esses enfoques permitem uma discussão das teorias em quatro grupos: instrumentais, políticas, integradoras e éticas.

As teorias instrumentais abordam a empresa exclusivamente como instrumento de criação de riqueza e suas atividades sociais são usadas como meio para alcançar a lucratividade. As teorias políticas fazem referências ao poder das empresas nas sociedades e suas responsabilidades no cenário político.

As teorias integradoras que abordam as empresas como centro da captação, identificação e respostas as demandas sociais. Com esse elo, busca-se a legitimação social e maior ascensão e prestígio social.

As teorias éticas referenciam-se nas responsabilidades éticas das empresas para com a sociedade, baseadas em princípios que expressam na necessidade da construção de uma sociedade melhor.

Nas suas ações, o Instituto Ethos (2009) busca disseminar a prática de RS no ambiente organizacional, caracterizando a ação socialmente responsável da seguinte forma: Responsabilidade Social Empresarial (RSE) é a forma de gestão que se define pela relação ética e transparente da empresa com todos os públicos com os quais ela se relaciona e pelo estabelecimento de metas empresariais que impulsionem o desenvolvimento sustentável da sociedade, preservando recursos ambientais e culturais para as gerações futuras, respeitando a diversidade e promovendo a redução das desigualdades sociais.

Entretanto, mesmo não existindo unanimidade na definição do termo, deve-se adotar nas organizações um significado que se refere às decisões tomadas nos negócios norteadas por valores éticos, legais, respeito às pessoas, comunidades e meio ambiente. Assim, o desempenho das organizações nesse contexto deve estar associado a uma posição ativa e inovadora, para enfrentar os desafios crescentes como organismo de desenvolvimento e bem estar social.

Reconhecer os benefícios das práticas de RS tem sido o enfoque das abordagens de muitos autores, embora com visões diferentes. Para Carrol (1991), a concepção de RSE, é concebida em quatro tipos de responsabilidade: econômica, legal, ética e discricionária ou filantrópica.

A responsabilidade econômica relaciona-se pelo objetivo com que foram criadas, ou seja, como entidades econômicas destinadas a fornecer bens e serviços aos membros da sociedade. O lucro foi estabelecido como o incentivo primário para o empreendedorismo.

$\mathrm{Na}$ responsabilidade legal espera-se o respeito às leis e regulamentos promulgados pelo poder público municipal, estadual e federal. Essa responsabilidade é considerada numa perspectiva de visão ética normatiza concebida 
a partir da incorporação das noções básicas de procedimentos, conforme estabelecidas pelos legisladores.

A ética como outro tipo de responsabilidade, incorpora as normas ou expectativas que refletem uma preocupação com os consumidores, colaboradores, acionistas e comunidade, em consonância com o respeito ou a proteção dos direitos e valores morais.

A responsabilidade filantrópica inclui uma participação mais ativa em atos ou programas para promover o bem-estar humano. A figura 2 apresenta esse modelo, onde as responsabilidades são ordenadas da base para o topo em função de sua magnitude relativa e da frequência dentro das quais os gestores lidam com cada aspecto.

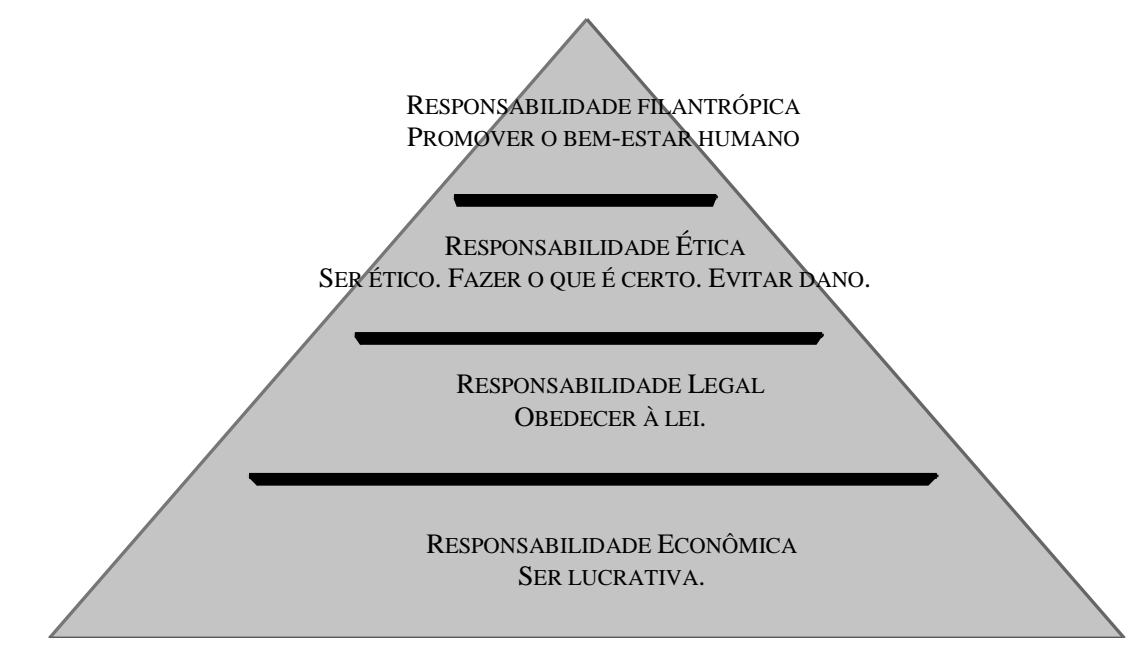

Figura 2 - Os quatro tipos de responsabilidade de social das empresas Fonte: Carroll (1991).

As concepções de RSE, segundo Carroll (1991), são definidas da seguinte forma:

1. A responsabilidade econômica relaciona-se pelo objetivo com que foram criadas, ou seja, como entidades econômicas destinadas a produzir bens e serviços de que a sociedade necessita e quer, a um preço que possa garantir a continuação das atividades da empresa, de forma a satisfazer suas obrigações com os investidores e maximizar os lucros para os seus proprietários e acionistas;

2. Responsabilidade legal define o que a sociedade considera importante com respeito ao comportamento adequado da empresa. Ou seja, esperase que as empresas que atendam as metas econômicas dentro da estrutura legal e das exigências legais, que são impostas pelos conselhos locais das cidades, assembleias legislativas estaduais e agências de regulamentação do governo federal; 
3. Responsabilidade ética inclui comportamentos ou atividades que a sociedade espera das empresas, mas que não são necessariamente codificados na lei e podem não servir aos interesses econômicos diretos da empresa. O comportamento antiético, que ocorre quando decisões permitem a um indivíduo ou empresa obter ganhos à custa da sociedade, deve ser eliminado. Para serem éticos, os tomadores de decisão das empresas devem agir com equidade, justiça e imparcialidade, além de respeitarem os direitos individuais;

4. Responsabilidade discricionária ou filantrópica é puramente voluntária e orientada pelo desejo da empresa em fazer uma contribuição social sem ser imposta pela economia, pela lei ou pela ética. A atividade discricionária inclui: fazer doações a obras beneficentes; contribuir financeiramente para projetos comunitários ou para instituições de caridade que não oferecem retornos para a empresa e nem mesmo são esperados.

Considerando as questões abordadas, o empresário Oded Grajew criou em 1998, o Instituto Ethos de Empresas e Responsabilidade Social, que objetiva disseminar a prática social através de publicações, experiências vivenciadas, programas e eventos para seus associados e interessados em geral, procurando contribuir para o desenvolvimento social, econômico e ambiental de uma nova cultura empresarial baseada na ética, nos princípios e valores.

Grajew (2000), afirma que as empresas e seus líderes têm um papel fundamental diante deste cenário. Em poder das corporações está o capital, a capacidade de gestão dos recursos e, sobretudo, um extraordinário estoque de talentos, fator decisivo em qualquer processo de transformação. Para desempenhar esse papel, é preciso que o mundo corporativo siga alguns princípios elementares.

Em primeiro lugar, é urgente tomar consciência da realidade que nos rodeia e do fato de que fazemos parte dela. Em seguida, é preciso entender o conceito de RS como o compromisso de cada um com a qualidade de vida, com a preservação da natureza e com uma sociedade mais justa.

Não se pode deixar de considerar, entretanto, outras possíveis definições que geram novos quadros de modelos conceituais, particularmente aqueles associados à RS que tratam das relações éticas e morais das organizações. Nesse caso, como se trata de questões muito subjetivas, são desenvolvidos modelos teóricos que objetivam alinhar o comportamento da organização, de modo a permitir a visualização do estágio em que se encontra.

Para Ashley (2003) o termo RS pode ser definido como: o compromisso que a organização deve ter com a sociedade, expresso por meio de atos e atitudes que as afetem positivamente, de modo amplo, ou a alguma comunidade, de modo 
específico, agindo proativamente e corretamente no que tange a seu papel específico na sociedade e a sua prestação de contas para com ela.

A partir do modelo tridimensional de RSE desenvolvido por Wood (1991), Ashley (2003) construiu um novo modelo chamado Análise do Conteúdo da Comunicação de Estratégias de Responsabilidade Social Empresarial - ACCERSE, que possibilita conhecer como as ações de RSE são estabelecidas nas organizações. O resultado é obtido através da observação da comunicação empresarial. O referido modelo objetiva analisar como se processa a comunicação da estratégia relacionada com RSE, os quais são agrupados, segundo Ashley (2003), em quatro temas assim distribuídos:

1. Princípios e Diretrizes: trata do tema relacionado com a difusão dos valores da RSE, regras de gestão que norteiam a conceituação da RSE e como é entendida pela organização;

2. Processos Organizacionais: o tema é indicado para acompanhar a forma como a organização incorpora os princípios e diretrizes da RSE na rotina do dia-a-dia;

3. Projetos e ações Específicas: objetiva explicar como as políticas e programas da organização estão relacionados diretamente a RSE;

4. Transparência e Publicidade: temática mais relevante no processo de comunicação e conhecimento dos assuntos relativos à RSE.

Nessa visão, observa-se que o modelo Ashley de RSE tem um caráter institucional e que pode ser trabalhado em instituições públicas, privadas e especialmente na proposta de gestão de recursos naturais. É importante entender que os atores sociais são chamados a refletir sobre novos conceitos e modelos de gestão que são desenvolvidos e que colocam como possibilidade resguardar a preservação ambiental $\mathrm{e}$ as melhorias dos processos voltados para o desenvolvimento sustentável.

Para que essas diretrizes e ações de Responsabilidade Social sejam concretizadas é necessário que as organizações se comprometam de maneira diferenciada com a construção de um novo paradigma de gestão, especialmente no que se refere a construção da cidadania, tornando-os sensíveis aos problemas sociais que os rodeiam. Isso será possível na medida em que as práticas de gestão, bem como a participação dos atores sociais estejam comprometidas com a construção de iniciativas de responsabilidade social.

Tais mudanças devem estar alinhadas com a organização de forma sistêmica no processo de modernização e no estabelecimento de critério valorativo para o desenvolvimento organizacional, analisando-se então, suas estruturas básicas, seus processos de trabalho e sua missão: no contexto social e no significado da organização em todos os níveis.

A implantação de ações relacionadas com novas práticas, processos, sistemas e atividades de forma contínua são irreversíveis nas organizações, implicando, 
portanto, na criação de uma cultura própria, envolvendo não apenas novas relações com a sociedade, mas também novas formas de interação internas e novas relações de poder.

\section{A interface entre Responsabilidade Social e a Gestão de Recursos Naturais}

De acordo com descrição do modelo GREEN e da RS, no contexto da gestão de recursos naturais, é possível identificar nos pressupostos considerados no estudo a interface da RS na gestão de recursos naturais. A maioria das definições apresentadas sobre RS reforça a ideia de que a ética, a cultura e os valores morais são inseparáveis de qualquer noção de RS (CARROL, 1991; ASHLEY, 2003). O mesmo com relação ao modelo GREEN que interage com dimensão dos modos de apropriação e dos processos decisórios na perspectiva de um sistema de valores (VIEIRA E WEBER, 2002).

De acordo com Ashley (2003), os valores morais dizem respeito a crenças pessoais sobre comportamento eticamente correto ou incorreto, tanto por parte do próprio individuo quanto com relação aos outros. A moral pode ser vista como um conjunto de valores e de regras comportamentais que as coletividades, sejam elas nações, grupos sociais ou organizações, adotam por julgarem corretos e desejáveis.

Os valores são os critérios de resolver as dúvidas dos atores sociais a respeito do modo de conduta em determinadas situações, quer seja porque a situação em si não deixa claro qual é a conduta a ser seguida, ou o desejo do individuo vai numa direção oposta as regras ou as pressões sociais, e as sanções sociais por ignorá-las ou transgredi-las seriam mais fortes (PEREIRA, 2006).

Os valores éticos, conforme Carroll (1991), assumem uma importância significativas que é vista como outra responsabilidade, pois incorpora as normas ou expectativa, as quais vão refletir na preocupação com os consumidores, colaboradores, acionistas e comunidade.

Assim observa-se que os valores podem ser definidos como crenças e pressupostos básicos de uma organização, possuindo atributos de conteúdo e de intensidade. Os atributos de conteúdo determinam o modo de conduta ou de valores finais e os atributos de intensidade correspondem ao quanto ele é importante.

Nesse contexto, a gestão de recursos naturais incorpora no sistema de valores os pressupostos da RS, referente às obrigações da organização seja ela econômica ou social, mas que terá de estabelecer normas e regulamentos que possam classificar e ordenar o uso dos recursos naturais, modos de apropriação e os processos decisórios.

A abordagem da gestão de recursos naturais resultante desse estudo tem a RS como instrumento norteador para as variáveis: responsabilidade social; representações e percepções; normas e classificações: organização econômica e social; modos de apropriação; processos decisórios e usos dos recursos, como estão expostos na figura 3. 


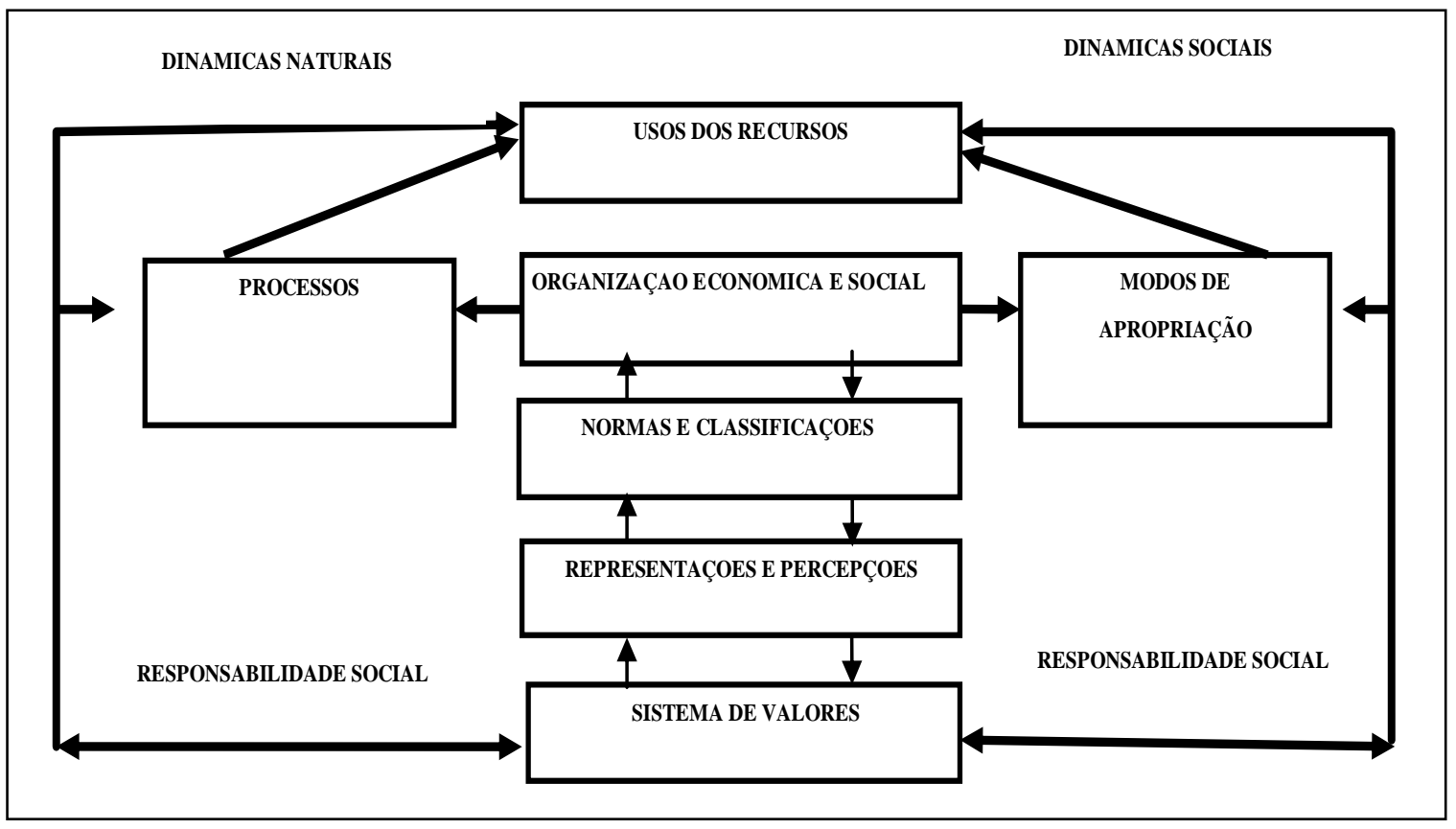

Figura 3. Modelo compacto de análise GREEN.

Fonte: Adaptado Vieira e Weber (2002).

O sistema de valores é o condicionante mais importante dentro desse contexto, pois dele são norteadas as formas de condutas, metas e ações dos indivíduos e das organizações. É nesta variável que a interface da responsabilidade social se incorpora a gestão de recursos naturais, na perspectiva de uma interação social e nos requisitos para a sobrevivência dos grupos.

As representações e percepções dos atores sociais estão sob a influência do sistema de valores e buscam uma nova forma de compreender o uso dos recursos naturais, ao mesmo tempo em que provocam alteração no comportamento e nas atitudes em relação a participação e a responsabilidade na gestão compartilhada.

As normas e classificações funcionam como um processo regulador nas ações de uso dos recursos naturais e expressam o paradigma vigente na gestão e servem como instrumento para o planejamento. Para Pereira (2006), as normas são expectativas transformadas em exigências e juntamente com os valores são elementos de integração, uma vez que todos os praticam.

A organização econômica e social é o espaço social, onde as pessoas interagem no sentido de gerir os recursos para produzir resultados. Portanto, pode-se afirmar que nenhuma organização sobrevive se não atende adequadamente ao meio ambiente na qual está inserida. Para Pereira (2006) as organizações expressam seus valores de diversas formas: em seus estatutos, nas reuniões dos conselhos diretivos, 
em suas publicações, nas declarações públicas de seus representantes, em seus sítios na Internet.

O processo decisório no modelo do GREEN se contrasta com os paradigmas tradicionais de análise, pois focaliza os interesses dos atores sociais na dinâmica da gestão. Os pressupostos do sistema de valores são imperativos na formulação de políticas de longo prazo.

Segundo Ollagnon (2002), a titularidade do patrimônio, aqui designada como modos de apropriação, é compreendida como o estabelecimento de uma relação com elementos materiais e imateriais do seu meio ambiente e que cada ator social gera seu patrimônio através do envolvimento simultâneo com todas as categorias de titulares, sejam elas pessoa física, jurídica e comunidade.

Assim, considerando os recursos naturais como patrimônio individual e compartilhado por todos, visualizam-se novas possibilidades de percepção e atitudes dos atores sociais envolvidos, no que se refere a qualidade do meio ambiente na perspectiva do bem comum do conjunto da sociedade.

\section{CONSIDERAÇÕES FINAIS}

Pode-se concluir que a maioria das definições de responsabilidade social e organização e gestão estão focadas na contemporaneidade em que a sociedade e as organizações estão inseridas. Essas considerações reforçam as tendências de gestão que aponta para uma necessidade de uma visão interdisciplinar que garanta o bom funcionamento dos sistemas de gestão, com participação ativa dos atores sociais, norteados por um sistema de valores, que por sua vez regulamentam as relações mútuas entre as pessoas e/ou organizações.

Assim sendo, o estabelecimento de propostas e prioridades para o uso dos recursos naturais deve ser norteado pelo modelo compacto de análise GREEN, no qual a sua base está sedimentada pelo sistema de valores. Essa adoção passa, sobretudo, pela forma como instrumentos institucionais e organizacionais se compatibilizam com os desafios e preocupações com o futuro e estão coerentes com a concepção de RS da gestão.

Como o objetivo proposto neste trabalho foi o de apresentar um ensaio teórico evidenciando a responsabilidade social na gestão de recursos naturais, considera-se que o mesmo tenha sido atendido, pelo fato de ter sido abordada a importância dos valores morais e éticos no funcionamento de um sistema de gestão, as organizações como fontes aglutinadoras de pessoas em busca de soluções de problemas e, por fim a melhoria da qualidade da gestão de recursos naturais, em decorrência da inclusão de novos métodos de gestão com base na responsabilidade social.

Portanto, pode-se afirmar que a interface da responsabilidade social na gestão de recursos naturais está centrada no sistema de valores que norteia os indivíduos e as organizações. 


\section{REFERÊNCIAS}

ASHLEY, Patricia Almeida. Ética e responsabilidade social nos Negócios. São Paulo: Saraiva, 2003.

BURSZTYN, Marcel e PERSEGONA, Marcelo. A grande transformação ambiental: uma cronologia da dialética homem-natureza. Rio de Janeiro: Ed. Garamond Ltda, 2008.

BUSINESS SOCIAL RESPONSIBILITY (BSR). Business brief: intangibles and CSR. Disponível em: <http://bsr.org/reports/BSR_AW_Intangibles-CSR.pdf/>. Acesso em: 02, outubro, 2009.

CARROL, B. Archie. The Pyramid of Corporate Social Responsibility: toward the moral management of organizational stakeholders. Business Horizons, July-August 1991.

CARVALHO, A. Victor de. Responsabilidade penal por danos ambientais. In.: JÚNIOR, J. S. GALVÃO, Fernando. Direito Ambiental: na visão da magistratura e do Ministério Público. 616 p. Belo Horizonte, MG. Del Rey, 2003.

CRUZ, Lucia Maria Marcellino de Santa, Responsabilidade social Visão e intermediação da mídia na redefinição do público e do privado. Dissertação de Mestrado apresentada ao Programa de Pós-Graduação em Comunicação e Cultura, Escola de Comunicação, Universidade Federal do Rio de Janeiro. 2006.

CURY, Antonio. Organização e métodos: uma visão holística. 8 ed. São Paulo: Atlas, 2006.

EGRI, Carolyn P.; PINFIELD, Laerence T. As organizações e a biosfera: ecologia e meio ambiente. In: Handebook de estudos organizacionais. São Paulo: Atlas, 1998.

FERREIA, A. B. H. Novo dicionário Aurélio da língua portuguesa. 3. ed. Curitiba: Positivo, 2004.

FIGUEIREDO, Andrea Cátia Ferreira de. A responsabilidade Social no Setor Petrolífero: $o$ caso da BP e da Chevron. 2012. Dissertação (Mestre em Ciências Empresariais). Universidade Fernando Pessoa. Porto. 2012.

GARRIGA, Elisabet; MELÉ, Domènec. Corporate social responsibility theories: mapping the territory", Journal of Business Ethics 53: 51-71, 2004.

GRAJEW, Oded. Somos todos responsáveis. Revista Exame. ed. 728, p. 31. Caderno especial. Guia de Boa Cidadania Corporativa. São Paulo, 2000. 
GODARD, Olivier. A gestão integrada dos recursos naturais e do meio ambiente: conceitos, instituições e desafios de legitimação In: VIEIRA, Paulo Freire e WEBER, Jaques. Gestão de Recursos Naturais Renováveis e Desenvolvimento: Novos Desafios para a Pesquisa Ambiental. São Paulo: Cortez, 2002.

INSTITUTO ETHOS. Responsabilidade Social Empresarial. Disponível em: <http://www3.ethos.org.br/conteudo/participacao-e-representabilidade-social/>. Acesso em: 13/10/2009.

MELO NETO, Francisco Paulo; FROES, César. Responsabilidade social e cidadania empresarial: a administração do terceiro setor. 2 ed. Rio de Janeiro: Qualitymark, 2005.

NADAS, Peter. Ética na administração: responsabilidade social do administrador. Fórum de responsabilidade e balanço social. São Paulo: SESI, 2002.

OLLAGNON, Henry. Estratégia patrimonial para a gestão dos recursos e dos meios naturais. Enfoque integrado da gestão do meio rural. In: VIEIRA, Paulo Freire e WEBER, Jaques. Gestão de Recursos Naturais Renováveis e Desenvolvimento: Novos Desafios para a Pesquisa Ambiental. São Paulo: Cortez, 2002.

PEREIRA, Edson Luiz. Valores individuais e valores organizacionais: uma contribuição para o estudo de congruências. 2006. 134 f. Dissertação apresentada ao programa de PósGraduação da Universidade Presbiteriana Mackenzie. São Paulo.

REBOUÇAS, Fernando. Responsabilidade Socioambiental. Disponível em: http://www.infoescola.com/sociedade/responsabilidade_socioambiental. Acesso em 09/03/2011.

ROBBINS, Stephen Paul. Administração: mudanças e perspectivas. São Paulo: Saraiva, 2000.

SOUZA, Miriam de Almeida. A Política legislativa do consumidor no direito comparado. Belo Horizonte: Edições Ciência Jurídica, 1996.

STONER, James A. F., FREEMAN, R. Edward. Administração. 5.ed.: Ed. LTC, Rio de Janeiro, 1999.

UNIVERSIDADE FEDERAL DE CAMPINA GRANDE. Robert Owen. Disponível em: <http://www.dec.ufcg.edu.br/biografias /Robert Owe.htm>. Acesso em: 09/03/11.

VIEIRA, Paulo Freire, e WEBER, Jaques. Introdução Geral: sociedade, natureza e desenvolvimento viável. In: VIEIRA, Paulo Freire e WEBER, Jaques. Gestão de recursos naturais renováveis e desenvolvimento: novos desafios para a pesquisa ambiental. São Paulo: Cortez, 2002. 
NASCIMENTO, J. M. L. do; CURI, R. C. A Interface da Responsabilidade Social...

VIEIRA, Paulo Freire; BERKES, Fikret; SEIXAS Cristiana S. Gestão integrada e participativa de recursos naturais: conceitos, métodos e experiências. APED, Florianopolis, 2005.

WOOD, Donna J. Corporate social performance revisited. Academy of management Review, Boston, v. 16, n. 4, p. 691-718, Oct. 1991. 